\title{
Centralisatie versus regionalisatie van de prostaatkankerzorg in Nederland
}

\author{
Arno D. H. Geboers ${ }^{1}$ Carl J. Wijburg ${ }^{2}$ A. H. J. (Geert) Smits ${ }^{2}$ Philip C. Weijerman ${ }^{2}$ Bin K. Kroon ${ }^{2}$
}

Published online: 13 September 2017

(C) The Author(s) 2017. This article is an open access publication.

Samenvatting Er is veel discussie over de vraag of centralisatie de prostaatkankerzorg in Nederland kan verbeteren. Kwaliteit verbetert immers naarmate je iets vaker doet. Echter, hoe ver dient een centralisatie te worden doorgevoerd? Zijn twee klinieken, naar het voorbeeld van de Martini-Klinik in Hamburg met 1000 prostaatoperaties per jaar, haalbaar voor Nederland? De argumenten hiervoor zijn mager en onwenselijke neveneffecten zijn onvoldoende onderzocht. Regionale samenwerking lijkt meer mogelijkheden te bieden voor efficiënte en doelmatige zorg.

Trefwoorden centralisatie - regionalisatie . prostaatcarcinoom $\cdot$ RALP $\cdot$ robotgeassisteerde prostatectomie $\cdot$ kwaliteit

\section{Centralisation versus regionalisation of care for prostate cancer in the Netherlands}

\begin{abstract}
Recently, a discussion emerged whether centralization of the treatment of prostate cancer in the Netherlands can improve the quality of care. It is well known that practice and experience have a positive influence on the results. However, how far should centralization be implemented? Are two clinics, following the example of the Martini Clinic in Hamburg, with 1000 prostate operations a year, achievable for the Netherlands? The arguments are lean and undesirable side effects insufficiently investigated.
\end{abstract}

\footnotetext{
drs. Arno D. H. Geboers

a.geboers@slingeland.nl

1 afdeling Urologie, Slingeland Ziekenhuis, Doetinchem, Nederland

2 afdeling Urologie, Rijnstate Ziekenhuis, Arnhem, Nederland
}

Regional cooperation aims to provide more opportunities for adequate and efficient care.

Keywords prostate cancer - regionalization · centralization - RALP · robot assisted prostatectomy · quality

\section{Introductie}

In Nederland is recentelijk veel discussie over de vraag of centralisatie van prostaatkankerzorg, en met name de radicale prostatectomie, de uitkomst van zorg kan verbeteren. De discussie werd geïnitieerd door professor Bangma in een visiestuk in de Urograaf.

De belangrijkste uitdaging voor Nederland zou liggen in een centralisatie in twee megaklinieken, waar per centrum minstens 1000 prostaatoperaties per jaar uitgevoerd moeten worden. Een belangrijke motivatie voor deze visie is de stelling dat de kwaliteit toeneemt wanneer je iets vaker doet. Als belangrijke bron voor de stellingname werden de resultaten van de radicale prostatectomie uit de MartiniKlinik in Hamburg genoemd. Daarbij werden twee bronnen met elkaar vergeleken: de uitkomst van de IKNL-registratie (Integrale Kankerregistratie Nederland) en de resultaten, zoals deze zijn gepubliceerd door de Martini-Klinik zelf.

\section{Wetenschappelijke en logistieke haken en ogen}

Het is heel interessant om gegevens met elkaar te vergelijken, maar daarbij dien je je wel bewust te zijn van het verschil in methodiek van de onderliggende registratie. Het voert zeker te ver om hieruit conclusies te trekken met dermate vergaande consequenties. Door Bangma zelf werd al 
aangegeven dat de vergelijking niet rechtmatig is. Het is niet duidelijk of de patiëntengroepen vergelijkbaar zijn. De perioden die vergeleken worden, komen niet overeen. In het ene geval zijn het de resultaten van een centrum, met waarschijnlijk een meer uniforme wijze van verslaglegging door enkele onderzoekers, in het andere geval zijn het de gegevens die zijn verzameld door vele IKNL-medewerkers uit meerdere ziekenhuizen.

Reeds in onze opleiding kregen we met de paplepel ingegoten dat pas echt conclusies mogen worden getrokken uit (het liefst dubbelblind) gerandomiseerde onderzoeken. Op zijn minst dient stratificatie plaats te vinden van patiëntengroepen en dienen onderliggende definities hetzelfde te zijn. Hoe en door wie werden bijvoorbeeld positieve snijvlakken, incontinentie en impotentie gemeten?

Illustratief is de wijze waarop het percentage negatieve snijvlakken in Hamburg tot stand komt: wanneer in de Martini-Klinik een peroperatieve vriescoupe positief is, volgt een radicale excisie van de hele neurovasculaire bundel en worden de snijvlakken als negatief afgegeven. Dit percentage komt in Nederland op een andere manier tot stand.

Er is een betrekkelijke wetenschappelijke onderbouwing van de resultaten uit Hamburg, zoals aangehaald door Bangma. Zij komen tot percentages positieve snijvlakken bij T2/incontinentie/impotentie van 7\%, 7,5\% en $34,7 \%$. Een snelle internetsearch naar de resultaten van een ander groot prostaatcentrum in Duitsland, het 'robotcentrum' in Gronau levert $3,1 \%, 5,3 \%$ en $32,2 \%$ op. Zowaar beter dan Hamburg. Zegt dit iets? Nee! De resultaten zijn door beide klinieken zelf gemeten en niet geverifieerd, en zeker in het laatste geval, hoofdzakelijk bedoeld om patiënten te werven.

We kunnen een stuk waaraan zoveel wetenschappelijke en logistieke haken en ogen kleven, niet tot norm verheffen voor het beleid van de prostaatkankerzorg in Nederland. Om in de beeldspraak van Bangma te blijven: "De geest is uit de fles." Daarom is het nu van belang om een brede discussie te voeren, waarbij alle argumenten worden benoemd.

\section{De vrucht van ervaring gaat verloren}

Bij centralisatie zal de ingreep hoofdzakelijk met de DaVinci Robot worden verricht. De RARP is in veel klinieken de meest frequent uitgevoerde urologische ingreep, die een belangrijk onderdeel is van een totaalpakket aan ingrepen waarmee robotchirurgen hun handvaardigheid op kunnen bouwen en onderhouden. Daarnaast gaat het ook in de robotchirurgie om teamwerk. De ervaring die wordt opgedaan bij de RARP is van groot belang bij de robotgeassisteerde cystectomie, de (partiële) nefrectomie en bij urologisch-reconstructieve ingrepen. Zo is de apicale dissectie bij een zenuwsparende cystectomie voor het aanleggen van een neo- blaas, van minstens even groot belang als bij een RARP. Bij centralisatie van de prostatectomieën in enkele klinieken, zal de ervaring die hierbij wordt opgedaan niet gebruikt kunnen worden voor een RARC met een neoblaas. Andersom geldt ook dat er veel minder gebruikgemaakt kan worden van ervaringen en vernieuwingen die worden opgedaan bij de andere robotoperaties, bijvoorbeeld de robotgeassisteerde cystectomie en partiële tumornefrectomie.

\section{De risico's van supercentralisatie}

Door ervaring te centraliseren, dreigt een supercentralisatie te ontstaan voor meerdere (robotgeassisteerde) laparoscopische ingrepen en zal er een systeem ontstaan zoals in Duitsland, waarbij 'Niedergelassenen' alleen nog maar de evaluatie van een urologische casus verrichten. Dat heeft grote en verstrekkende consequenties, die voorbij de grenzen van de urologie gaan. Iedere uroloog wordt immers ook met enige regelmaat peroperatief in consult gevraagd bij een lastige chirurgische of gynaecologische ingreep. Hierbij dient dan een laesie van ureter, blaas of urethra te worden hersteld, waarbij vaak een beroep wordt gedaan op de chirurgische ervaring van de uroloog. Bij verdergaande centralisatie zal een volgende generatie urologen deze problemen niet meer op kunnen lossen, simpelweg omdat ze deze organen nooit meer van dichtbij hebben gezien. De consequenties voor de patiënten die het betreft, laten zich raden.

\section{De meerwaarde van centralisatie}

De meerwaarde van centralisatie zou met name gelegen zijn in het snel kunnen evalueren van gegevens. In Nederland bestaat sinds meerdere jaren de (decentrale) kwaliteitsregistratie, waarbij centra hun eigen gegevens invoeren in een landelijke database. Hoewel dit een grote stap vooruit is, heeft deze opzet nog de nodige beperkingen. De gegevens worden door de ziekenhuizen zelf ingevoerd en er zijn nog geen duidelijke afspraken over evaluatie en rapportage. Er worden ook nog geen consequenties verbonden aan resultaten die onder de norm vallen. Op dit moment werkt de Werkgroep Oncologische Urologie (WOU) aan de mogelijkheid om de kwaliteitsregistratie te laten verrichten door het IKNL. Er zal een AUC/DMC (Auditing en Data Monitoring Commissie) worden opgericht, die de resultaten van registratie gaat bewaken met de autorisatie om locale audits uit te voeren bij centra die achterblijven bij de norm. In de najaarsvergadering van de NVU 2017 moet de aanstelling van deze commissie worden geaccordeerd. 
Hier staat een advertentie.

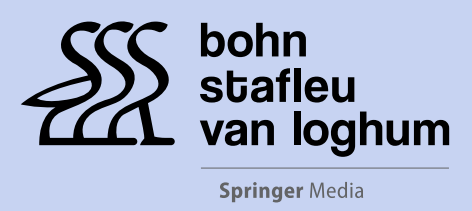

Houten 2017 
Hier staat een advertentie.

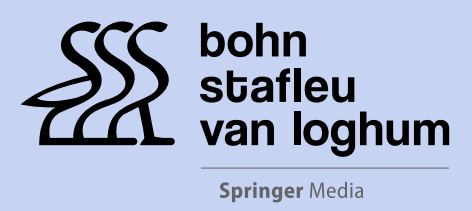

Houten 2017 
Hier staat een advertentie.

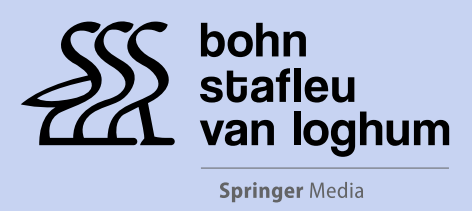

Houten 2017 
Hier staat een advertentie.

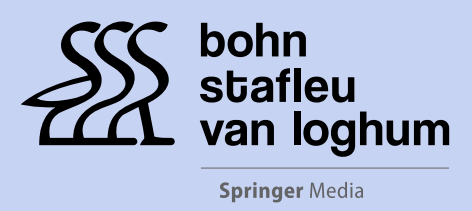

Houten 2017 


\section{Regionale en landelijke samenwerkingsverbanden}

Het Santeon-initiatief en het Kwaliteitsverband prostaatpartners vormen een groot samenwerkingsverband binnen Nederland, waarbij meerdere topklinische ziekenhuizen zijn aangesloten. Het is de verdienste van het Santeon dat voor meerdere ziektebeelden uniforme criteria voor het meten van kwaliteit zijn opgesteld. Dat rechtvaardigt naar ons idee niet dat daardoor enkele centra het exclusieve recht zouden moeten krijgen om als enige deze ingrepen uit te voeren. Dat zou voorbijgaan an veel andere belangrijke regionale initiatieven, zoals de Alliantie Regionale Top Zorg (A.R.T.Z.), een samenwerkingsverband tussen meerdere ziekenhuizen in Gelderland, met een adherentie van ruim een miljoen patiënten.

Dat het standpunt van Bangma en de lobby van de Santeon-groep in Nederland iets heeft losgemaakt, blijkt ondertussen ook uit het initiatief van zorgverzekeraar Zilveren Kruis, dat samen met andere zorgverzekeraars een verzoek 'om informele zienswijze' heeft ingediend bij de Autoriteit Consument \& Markt (ACM) om gezamenlijk de prostaatkankerzorg in te mogen kopen, met als doel deze zorg te concentreren in twee centra. In Skipr van 9 april jl. stellen zorgverzekeraars dat ze deze route voor meer laagvolumezorg willen gaan volgen.

Bij monde van de heer Noorlach reageert de Nederlandse Vereniging van Ziekenhuizen (NVZ) in een brief aan Zilveren Kruis dat hier echter (met ruim 2000 behandelingen per jaar) geenszins sprake is van laagvolumezorg.

Bovendien lijkt hier sprake van onwenselijke kartelvorming, die haaks staat op de basis van ons zorgstelsel van gereguleerde marktwerking, die juist gestoeld is op concurrentie tussen zorgverzekeraars.

Noorlach spreekt in zijn brief ook uit dat niet is aangetoond dat door de concentratie doelmatiger zorg kan worden geleverd. Dat wil zeggen, betere zorg tegen lagere kosten.

Daarnaast blijft het zeer de vraag of de succesfactoren van de Martini-Klinik, te weten de frequente analyse, feedback en benchmarking van behandelresultaten, samenhangen met de concentratie van prostaatkankerzorg. Hiervoor ontbreekt ieder bewijs.

Verder is het juist bedenkelijk dat de zorg slechts in twee centra wordt geconcentreerd, omdat daarmee iedere vorm van concurrentie wegvalt. Dat het systeem van superklinieken in Duitsland wel functioneert, komt hoofdzakelijk omdat daar nog voldoende concurrentie overblijft. Aan de verzekeraars wordt door de NVZ dwingend verzocht om niet op de besluitvorming van de Autoriteit Consument en
Markt (ACM) vooruit te lopen. Wij willen ons daar van harte bij aansluiten.

\section{De volumenorm}

Het blijft een punt van discussie wat het minimumaantal uit te voeren operaties per jaar moet zijn. Als we kijken naar de Nederlandse resultaten lijkt er boven de 100 patiënten per jaar in ieder geval geen verdere verbetering te zijn in positieve snijvlakken [1].

In juli 2017 is een artikel van Gersman et al. verschenen in de Journal of Urology [2]. In deze studie is de relatie tussen het volume per centrum en de uitkomsten van zorg onderzocht. Ruim 140.000 patiënten ondergingen tussen 2009 en 2011 een robotgeassisteerde radicale prostatectomie. In 2011 werd in $70 \%$ van de klinieken gemiddeld één patiënt per week geopereerd (50 per jaar). De kans op intra- en postoperatieve complicaties was duidelijk lager in de groep waar meer patiënten per jaar werden geopereerd, maar ook hier werd boven de 100 ingrepen per jaar nauwelijks nog verbetering van de uitkomsten gezien.

Het is waarschijnlijk dat de getallen uit 2009-2011 al weer gedateerd zijn. Door technische ontwikkelingen van de laatste jaren, zoals gebruik van een duo-console, simulatietechnieken én expertise door andere robotoperaties kan de leercurve veel korter zijn geworden.

In Nederland ligt de door de WOU vastgestelde norm op dit moment nog op 20 ingrepen per centrum per jaar. Deze grens zal in de komende jaren worden opgehoogd. Als we nu kijken naar de data van 2016 zouden, bij een norm van 50, ongeveer de helft van de ziekenhuizen afvallen. Daarmee zal verdergaande regionalisatie worden ingezet. Wanneer het zwaard van Damocles van de volumenorm wegvalt boven de hoofden van de overblijvende ziekenhuizen, kunnen die ziekenhuizen zich juist gaan inzetten voor betere kwaliteitsregistratie, waarbij niet de kwantiteit maar de kwaliteit - o. a. gemeten in PROMs - maatgevend zullen zijn. Naar ons idee is dat een wenselijker ontwikkeling voor prostaatkankerzorg in Nederland.

Open Access This article is distributed under the terms of the Creative Commons Attribution 4.0 International License (http:// creativecommons.org/licenses/by/4.0/), which permits unrestricted use, distribution, and reproduction in any medium, provided you give appropriate credit to the original author(s) and the source, provide a link to the Creative Commons license, and indicate if changes were made. 


\section{Literatuur}

1. Bangma C. Concentratie van prostaatkankeroperaties; uitloper van integrale zorg voor iedere prostaatkanker patiënt. Tijdschr Urol. 2016;6(Suppl. Najaarsvergadering):3-5.

2. Gershman B, Meier SK, Jeffery MM, et al. Redefining and contextualizing the hospital volume-outcome relationship for robot-assisted radical prostatectomy: implications for centralization of care. J Urol. 2017;198(1):92-9. drs. Arno D.H. Geboers uroloog

drs. Carl J. Wijburg uroloog

dr. A.H.J. (Geert) Smits uroloog

dr. Philip C. Weijerman uroloog

dr. Bin K. Kroon uroloog 